\title{
RESEARCH AND EDUCATION IN ACCESSIBILITY, DESIGN, AND INNOVATION (READI): A REFLECTION OF OUR FIRST YEAR
}

\author{
Alicia M. Gal ${ }^{1}$, Elizabeth Hoskin², Claire Davies ${ }^{2}$, Paul Marriage ${ }^{3}$, Adrian D. C. Chan ${ }^{1}$ \\ ${ }^{1}$ Department of Systems and Computer Engineering, Carleton University \\ ${ }^{2}$ Department of Mechanical and Materials Engineering, Queen's University \\ ${ }^{3}$ Ottawa Chapter, Tetra Society of North America \\ adrian.chan@carleton.ca
}

\begin{abstract}
Research and Education in Accessibility, Design, and Innovation (READi) is an interdisciplinary training program focusing on accessibility. With the first year of the READi completed, this paper provides an overview of the design of the program and reflections from the program, as experienced by two of its trainees. The training program appears to have increased the knowledge and skills of student trainees with regard to accessibility, while also enhancing many professional skills. In addition, there appears to be affective learning, uplifting the thoughts, opinions, and feelings of accessibility and inclusion, that foster a culture of accessibility. The program benefits from interdisciplinarity, collaborations with external stakeholders, engagement with real-world accessibility issues, and inclusion of people with disabilities.
\end{abstract}

Keywords: accessibility, disability, multidisciplinary, reflection

\section{INTRODUCTION}

One in five Canadians, over the age of 15 , has one or more disabilities (physical, sensory, cognitive, mental health-related) [1]. People with disabilities can face a number of barriers that prevent them from being able to fully participate in society. There is growing interest in accessibility and inclusion. Accessibility is a human right, recognized by the various human rights codes, including the United Nations Convention on the Rights of Persons with Disabilities [2]. The United Nations Envision 2030 Sustainable Development Goals challenge us to design our society to be fully inclusive of persons with disabilities including in such key areas as employment, physical infrastructure, and education [3]. In Canada, there are a number of provinces with accessibility acts (e.g., Accessibility for Ontarians with Disabilities Act [4], Accessibility for Manitobans Act [5], Nova Scotia
Accessibility Act [6], as well as the proposed federal Accessible Canada Act [7].

Creating an accessible and inclusive society is important for many reasons, including access to areas of employment, education, and recreation, and the need to accommodate the growing aging population [8]. In the area of computing education, instructors have learned that multiple experiences are required to keep students engaged in learning about design for access. These include field trips to interact with people with different abilities, guest speakers, movies, and other activities outside the classroom. [9]. Companies such as Microsoft, Google, Apple, Facebook, Adobe, and Yahoo! have helped form the Teaching Accessibility initiative (http://teachaccess.org). However, it appears that most students in engineering, computer science, information systems, and information technology are not being taught about accessibility [10,11]. The failure to include accessibility in the curriculum "perpetuates the cycle of ignorance among ICT developers and maintains the status quo of exclusion and marginalization of people with disabilities who cannot use the inaccessible products created by the ignorant developers" [12].

Research and Education in Accessibility, Design, and Innovation (READi; www.create-readi.ca) is an NSERC CREATE training program, with an objective to provide professional training and skills to students to enhance their preparedness for employment in the growing number of markets defined by accessibility requirements; particularly in the areas of engineering, ICT, and design [13]. READi, a collaboration between Carleton University, University of Ottawa, and Queen's University, started in September 2017 and has completed its first year. The first cohort of students was a multidisciplinary group of eight graduate students in biomedical engineering, mechanical engineering, computer science, design, human-computer interaction, and cultural mediations. 
The research in teaching accessibility, presented in [9], considers the pedagogical theory of "authentic learning". They refer to [14], who identified four aspects of pedagogy for effective "thick" authentic learning: (1) cultivating personal meaning for students; (2) relating to the real-world, outside school; (3) opportunities to think in the modes of a particular discipline, and (4) assessments that reflect the learning process. READi is an integrated solutions-oriented training program employing applied and experiential learning, which supports the different aspects of thick authentic learning. Through active collaborations with businesses, non-government organizations, accessibility experts, and people with disabilities, students engage in an interdisciplinary environment that focuses on real-world accessibility issues.

READi consists of five main program elements:

1) a graduate course, Accessibility and Inclusive Design;

2) Action Team Projects (ATP), an 8-month interdisciplinary project focused on real-world accessibility issues in collaboration with an external READi partner;

3) a 2-day retreat occurring midway through the Action Team Project;

4) interactive workshops; and

5) an annual symposium.

Using cuPortfolio, an electronic portfolio system (https://cuportfolio.carleton.ca/), students reflect upon their various learning experiences. Learning outcomes are assessed by the investigators in the following categories:

1) Apply inclusive design principles in research and development, particularly problem identification and ideation, in the creation of products, services, and/or environments that are usable by the largest number of people, regardless of age, gender, or abilities.

2) Employ a human-centered design process (including initial in-situ ethnographic user needs analysis and usability testing/validation), to advance our current understanding of design standards and/or principles in accessible design and human factors/ergonomic research in this area.

3) Interact within an interdisciplinary environment, including a diverse number of end-users in codesigning, and other participatory research and development activities.

4) Recognize and empathize with the diversity and uniqueness of end-user needs, including evolving motor, cognitive, and sensory capabilities.
5) Discuss accessibility from multiple perspectives, including technical, human rights, social, individual, and legislative.

In this paper, we have described the pedagogical design of the READi program, including the learning outcomes and educational strategies. This outlines the intentions of the READi faculty, which include co-authors Davies and Chan. Two of the co-authors reflect upon their experiences as students in READi training program: Hoskin is currently in her second year of her MASc in Mechanical Engineering at Queen's University, and Gal is currently in her second year of her $\mathrm{PhD}$ in Biomedical Engineering at Carleton University. The paper also includes some observations and perspectives from a READi collaborator, co-author Marriage, co-ordinator for the Ottawa Chapter of the Tetra Society (https://www.tetrasociety.org/).

\section{REFLECTIONS FROM GAL}

Do you ever go into something with a negative mindset, already excluding the potential for a good time? This was my case, my mindset, my exclusively negative attitude towards some very challenging aspects during my READi training this past year. Not what you were expecting to read was it? As I review my year, I hope to show why these first two sentences, as honest and connectable as they are true, why they are so important to this review. Why they were so important to my growth as a person. But more importantly, how the READi training program helped me develop into the person sharing this today. For, I am not the same person, nor do I have the same viewpoints or opinions about accessibility, design, and the world we live in as I did a year ago. This positive change is directly related to the READi training program and the people creating it.

Life is hard, and only becoming harder as we dangerously transition into an "insta" civilization. I see this slippery slope growing each year TAing first-year students. The course I TA is entitled Problem Solving and Computers, and the title itself implies the need for struggle, creating an initially stressful or negative environment. Many students have no faith in themselves during tasks where failure is a probable outcome. These students seem to desire instant approval for correct work, or answers to simple course related problems. Problems they can solve with a little bit of effort, for work that should not require review. Failure in this case is a red "error" message appearing on their screen, or numerous listed error messages in most cases. Maybe the presentation of the failure message itself is creating a barrier between the student and trust. Instead of an overwhelming cautionary warning, maybe we should seize an opportunity to impart positivity in expected failure, to instill productive educational feedback creating inclusivity through failure. Maybe then these students 
would be more willing to have a little faith and press the play button. It is only considered a failure if a lesson is not learnt. These students are learning are they not? This is what my READi training has taught me, to be more open-minded, to try and see the entire picture before creating a judgement.

From my READi training, I have matured my ability to empathize with a student's need for instant approval or fear of failure. I am able to better communicate with compassion, positivity, and awareness, to my large $(\sim 200)$ diverse student population, the idea of trial and error, and that failure is okay. I am no longer naïve enough to think I fully understand their feelings, because I do not and will not be able to. The READi workshop, led by Cathy Edwards, which discussed Empathy versus Sympathy guided me to this paramount acceptance. My ability to grow a relationship with a student and invoke the culture I wish to create in the classroom has benefited immensely from my READi training. Dr. Jesse Stewart's Music Communication workshop showed me how easy it is to reciprocate a feeling or awareness of context during communication. That in fact, we all know how to do this but we can often be exclusive or narrow-minded when using our communication skills box. Workshops like Music Communication, Mental Health Awareness, and Empathy versus Sympathy provided me the tools to become a more universal educator and more accessible to my students.

Each of the unique components of the Accessibility and Inclusive Design course, created by Dr. Lois Frankel, strengthened my communication and cultural awareness skill sets. Learning to strengthen your assessment skills was one of the key lessons taught throughout each component. My greatest influence from the design course came from my interview with Dr. Ali Arya. I feel this is where the shifting of my presumed mindset to a challenge began. In no means am I a negative person. I am the exact opposite, actually; overwhelmingly positive. But we all can become closed off during challenging situations; it is human. Dr. Arya was the one to broaden my viewpoint when setting my definition to words and concepts. Throughout his discussion based off life experiences, he unknowingly provided me guidance, which enabled my ability to become a more inclusive thinker, more openminded at the get go. If aid does not enable, are you really providing aid, or is it simply just a band-aid?

We as a society hide the hard stuff, while promoting the "insta" gratification feeling. We only share what we know people will like. This needs to stop, and what better time to change the trend than in a review of the program designed to do such that. Dr. Boris Vukovic cultivated the idea of awareness to me with his workshop on Mental Health Awareness. He presented shocking statistics on post-secondary mental health, or should I say the lack thereof. There is a real problem out there. With the world at our fingertips, people are not happy. I could not be more proud to learn from those pioneering aid initiatives to battle such struggles. More interestingly, those suffering are not reaching out to the avenues that are available to them. Despite the availability of these resources, they are not seen as accessible to those in need.

Now, that I have provided some insight on the type of education disseminated during my READi training, and that I am a positive and maturing inclusive thinker. I will now share how I made it through my very challenging Action Team Project (ATP). I like to look back at my ATP as my character defining training. They say, through the biggest challenges you gain the biggest growth; my ATP did such that. I am a stronger researcher, more aware communicator, and have started to become an advocate for those excluded from design because of the interactions throughout my ATP.

My ATP pushed me way out of my comfort zone numerous times. My ATP was conducted in an environment that was very new to me, and because of this I felt uneasy and sometimes depressed. These feeling were a combination of many factors, including struggling at times to be inspired by my task. In short, I designed and conducted a quality of life interview for low to non-verbal and/or low cognitive individuals with low to no mobility. My interview population consisted of individuals who could speak very few words, if any, with a minimal mobility boundary of head motion to a maximal mobility boundary of wheelchair confinement (assistance required). Inquiring about their daily experiences was an emotionally challenging task for me.

I put much thought and preparation into the interview questionnaire, including how I was to retrieve answers from each of my unique interviewees. Each time, I felt unprepared for that specific individual, despite modifying or altering my answer key, which was designed from various peer-reviewed resources. I tried to ensure each yes/no or numerical ranking response was followed by a feeling ranking to justify my recording or interpretation of their response. The answer key was mobile but never seemed adaptable enough for ease of use. With such diverse mobility and verbal abilities, it was challenging to create a universal answer key. My best suggestion was to have three answer keys: 1) on the clipboard backing, laminated for hygiene purposes, 2) individually laminated cards per answer style, and 3) an answer key with blanks below each response to record modified responses. Some interviewees preferred to use body gestures, such as head nods or sways instead of my answer key. In fact, I felt this engagement was a sign of comfort and trust with our conversation. With these three options one should be prepared for verbal-mobility-adaptability issues, including a muscular and/or mentally fatiguing interviewee. This was one of the greatest lessons I gained from my ATP, that an interview and an answer key must be adaptable (physically and/or mentally). That a person's actions and reactions can tell you more about their response if you 
truly engage and immerse yourself into the conversation. To make your communication skills more inclusive and universal. Through the use body language and gestures one can acquire a reasonable recording of a non-verbal response.

Without my READi training and support provided by my mentors Dr. Adrian Chan and Chantal Trudel, I am not sure I would have gained from this experience. I am not sure I would have had the tools to be inclusive enough for this very unique opportunity. If you have never had a conversation with someone who cannot speak and/or move, may I suggest you open yourself up to what they can teach you about your communication skill set. We may not realize that the manner in which we communicate can exclude others. Conversing with these individuals taught me many lessons about my personal communication style, many lessons that have since prompted me to adapt my communication style for the better.

Interacting with people with severe disabilities was a new experience for me. I found myself struggling with my emotions, actions, and reactions. As I reflect about my experiences, I believe these were fair responses to this new character defining adventure. Creating a positive relationship with my interviewees was always the main focus. I believe I was successful at achieving this goal. However, as I was able to discern a method of positive communication with each interviewee with help from my READi training, I was then able to become aware of the responses and the emotions tied to them. By becoming a more inclusive communicator, I also was more aware of how their response affected me. I became more empathic, which started a feeling that I had just become their voice; that connectedness made the work more meaningful and important to me. Personally, I could only conduct one interview a week as the entire process was emotionally challenging. I would like to point out that I did laugh on numerous occasions with each of my interviewees, and that we shared an emotional bond of understanding and trust through body language. The strength and growth I gained from my ATP has not only improved my ability to become an inclusive communicator, but has also introduced a new way of life for me. I am forever changed because of the lessons these individuals taught me.

I can truly see my own growth as I reflect on how my READi training has helped me to overcome my instinctively negative, or more accurately put, exclusive thoughts to a challenging situation. Through my struggles and lessons maybe you too felt a connection or awareness to one of your life experiences. Maybe we were able to grow together, sharing an honest bond over the difficult times in life. The times that helped us grow into who we are today. Maybe you have become more aware of your communication style and how you could help to create a more inclusive and universal way of communicating.
From each unique component of the READi training program, a lesson was taught. In combination, these lessons create an education foundation that can help create a more accessible world. Most importantly, the leaders chosen to educate were remarkable, they personally made the biggest impact on me. I am happy to report that I am very content with how my READi training made me feel during and also now after allowing the lessons to sink in and grow. I am stronger because of my training and I believe this is exactly the point of the READi program.

\section{REFLECTIONS FROM HOSKIN}

When I was 11 years old, I started volunteering as a counsellor in training at a day camp for children with special needs, where my interest in technologies for persons with disabilities began. Since then, I have continued to volunteer at various organizations providing health and arts programming to persons with disabilities, and have since spent over 1000 hours doing so. Throughout these experiences, my eyes have been opened to the need for accessibility in our society and the inequity that persons with disabilities face. This inspired me to pursue engineering as a career, so that I could promote design that enables equal access.

Throughout my undergraduate program I prioritized my interest in accessibility and volunteered for projects that were focused on assistive technologies, particularly technologies that promoted access to recreational activities. Although I did manage to build experience in the area of accessibility, I found that I needed to intentionally seek opportunities to do so. I found accessibility education in my undergraduate program to be minimal, which is likely typical to engineering programs across Canada [10][11]. Designing for a diverse set of users was often considered outside of a project scope, despite the prevalence of disability and the educational benefit of learning to design for diverse users [1]. In my last semester of my undergraduate program, I took the course Ergonomics and Design as an elective. This course was taught by Dr. Claire Davies (co-author), a READi co-applicant. One of the topics emphasized in this course was universal design. Universal design is an extremely useful strategy for ensuring that designs are usable by people of all abilities, and a theory that I would have greatly benefited from being able to practice applying earlier in my education. It concerns me to think that if I had not opted for this elective, I may have missed out on a concept that I have since found to be so important and useful.

Designing for a diverse set of users often results in products that are more thoroughly thought out and usable, while enabling equitable access. Designing for a diverse user group can also challenge students to think outside of the box to solve problems that are often overlooked, and 
build engineering and design skills in the process. Furthermore, integrating accessibility into engineering education may help promote diversity and inclusivity in the future. We all have biases that are formed based on previous experiences, and some students may have limited experience designing for or working with persons who have disabilities. By educating students about accessibility issues, they may be able to advocate for the importance of accessibility in their future careers and break the cycle of exclusion in design.

I chose to continue my education with the READi program because I wanted to build my knowledge and experience in the field of accessibility that I had not been able to build during my undergraduate degree. The READi program was the first opportunity I had heard of that would allow me to focus on my interest of designing for accessibility, while working with, and learning from, interdisciplinary teams. In particular, the opportunity to complete an action team project (ATP) was totally different from anything else I have ever worked on, providing a valuable opportunity to expand my experience.

The objective of my ATP was to access and share insights about the Canada Science and Technology Museum experience that emerged during fieldwork with people on the autism spectrum and their support persons. Through my ATP, I got to practice transferring skills to real-world scenarios, learn about stakeholder management and project management with multiple stakeholder involvement, and experience real world barriers to implementing changes. My ATP was outside of my comfort zone since it was very qualitative, where I have more experience in quantitative work, and it focused on a population I had little experience with. By applying knowledge to such a dynamic and challenging project, I learned a lot about my strengths and areas that require more development. The ATP was the most open ended project I have ever worked on, and this challenged my project management skills in particular. I learned about managing project goals and associated timelines to secure successful outcomes within a short period of time. It also required me to think through what my limitations due to gaps in my experience were, and how to address them. Additionally, I learned a great deal from diverse teammates who were in music therapy, computer science, and human-computer interaction. From my teammates, I learned how to manage a project with people who have very different working styles and varying perspectives on accessibility, and how to observe and challenge my own biases.

My introduction to working in the field of accessibility happened when I was a child, which meant that I encountered practices and attitudes that I did not yet have the critical thinking skills to ask informed questions about, or understand all the implications of. Although I am extremely grateful for the opportunities I had, I recognize that this introduction did leave me with biases, which I brought with me to the READi program. The READi program has been a useful tool for me to recognize and challenge these biases. Through the READi program, my eyes were opened to a wide variety of accessibility issues. I used to look at accessibility as black and white issues of access, and not complex issues that often battle conflicting needs such as budget constraints or heritage legislation. I also used to think of accessibility related careers as being limited to careers that provided 1:1 services to persons with disabilities. Through this program I have become aware of the diverse applications of accessibility related skills. I look forward to exploring these options in future careers upon graduation.

One other notable area of the READi program was affective learning outcomes. For me, empathy was the most significant affective learning outcome, which I gained through interactive workshops, presentations from persons with lived experiences, and interactions with other students in the program. Something that I did not expect to gain from this program was that discussions with other READi students led me to understand where people may come from with biases or prejudices against persons with disabilities or disability advocacy in general. From this, I am now able to be more understanding to where someone might come from in their beliefs that differ from mine. This has given me the skills to partake in informed discussions and hear opinions that are very different from my own without making judgements. I think that it is important to have these discussions if one wishes to advocate, and to promote education around accessibility issues.

I expect the READi program will impact my life after graduation in a few ways. First, understanding how accessibility related skills are widely applicable will enable me to market myself to future employers. I also expect that the skills I have built will be useful once I enter the workforce. In particular, I expect that my ATP experience will be useful wherever I end up, since the skills I learned are transferable to many different settings of employment. To name a few, these skills include project management, stakeholder management, and how to recognize my limitations. Most importantly, my involvement in this program has reinforced my passion for and interest in accessibility. I am going to prioritize accessibility in my future career through advocating for universal design, and intend to continue to work on assistive technology design projects in my free time. The READi program has been a wonderful opportunity, and I am very grateful for the experience.

\section{OBSERVATIONS FROM MARRIAGE}

During the READi retreat there was evident trepidation about how to meet the challenges and solve the problems inherent in the ATP tasks assigned. As Gal 
points out, there was the issue of difficult personal interaction and communication and for Hoskin it was defining qualitative requirements for an institution and its clients. The final ATP presentations in their value and strength, illustrated for me the strides that had been made by the teams in overcoming roadblocks through their creative problem solving and the gains in a fuller comprehension of what they as participants were capable of in working in this field of accessibility and inclusion. This transformation of Gal and Hoskin and other team members as a result of participating in READi, particularly the ATP portion, needs to be expanded to look at the impact on the world outside the university sector.

Stepping back we can see how organizations outside of the academic portion of READi have experienced the impact of the program in altering how accessibility and inclusion are being looked at. Institutions and developers, have generally taken the approach that for accessibility and inclusion issues, they will design and produce the product envisaged to meet needs. Those groups working with the READi students and those made aware, however, have learned the necessary engagement of the end user in the evolution of the product or process. The client becomes an imaginative participant connected with the research team to come up with what is required. When a READi graduate arrives on the scene of a company or organization mandated to offer products or approaches that provide accessibility and inclusion, they will bring with them their positive attitude about this need and a strong interest in seeking the best solution. Their knowledge, training, and experience in this field will allow them to apply creative problem-solving skills for the people that they are serving. A key factor will be their understanding of the limits to universal design and the need to accommodate the specific needs of end users. These may be multi-factored and the interdisciplinary approach taken through READi comes to the fore in helping address this requirement.

A further step back reveals the future that we are trying to create for people with disabilities and various limitations. The three fundamental aims of The Disability Foundation, of which the Tetra Society of North America is a part, are for this population to: 1) understand what is possible, 2) redefine what is possible, and 3) do what is possible (strategic plan) [14]. We are continually questioning and then discovering that more is possible than was previously imagined allowing us to venture into new arenas and do supportive things that overcome barriers and remove limitations. The ultimate aim is to ensure that the lives of people with disabilities and seniors with limitations are transformed to achieve meaningful and rewarding lives as full citizens. As noted earlier, we are taking what in the past would have been seen as momentous steps to assist people in accessibility and inclusion particularly through legislation. The private sector is coming on board with more technology to promote accessibility much of which can be adapted to individual situations. With this movement continuing in the public and private spheres, graduates of the READi program will be key players in sharing lessons learned and best practices and creating road maps for effective implementation of self-determination and individualized solutions for those needing it. The need is so great and the initial results of the READi program so positive in all aspects, including personal transformation and real world impact, that equivalent programming at the undergraduate level could be considered. Good grounding in theory of one's field with a healthy dose of experiential learning with external collaborators active in the accessibility sector makes for optimum potential employment opportunities in this growing field and related areas.

\section{DISCUSSION AND CONCLUSIONS}

Hoskin found that learning outcomes were achieved in a variety of different settings. Through workshops, she learned how to design accessible documents to meet inclusive design standards, she understood how the learned experience affects the design of devices and spaces, she learned interview skills when working with persons with disabilities, and a visit to Community Housing Kingston left her with some questions about meeting human rights perspectives when designing doorways and access environments. Her workshop in "Offering a deaf perspective" led her to enroll in a tenweek American Sign Language course. Finally, her action team project exposed her to a real-life project that involved reflecting on designs of museum environments to ensure inclusivity.

There was significant personal growth and development for Gal from the READi training program. Some of the main contributors to this learning, included working with people with severe disabilities and learning in a deeply interdisciplinary environment, which exposed her to different perspectives. Affective learning benefits from time and space for reflection, but also empathetic support from educators. Gal is now part of the The Queen Elizabeth Scholarship-Advanced Scholars program (https://carleton.ca/qes). As one of the outgoing scholars, Gal will be working in Mzuzu, Malawi and employing the knowledge and skills she has gained in accessibility and inclusion into a new context.

The READi training program appears to have been successful in delivering its intended learning outcomes. Students gained knowledge and skills related to accessibility, such as universal design. Arguably, just as important, was the learning in the affective domain, with students internalizing the value of accessibility. Accessibility and inclusion is not simply a destination, with success determined by a checklist of criteria. It is a process with a commitment towards continual 
improvement, which needs the development of a culture of accessibility and inclusion. The report for the third review of AODA notes, "What's needed isn't so much compliance as 'accessibility mindfulness"” [16]. Students also developed professional skills (e.g., communications, teamwork, time management, lifelong learning), with increased capacity to work across disciplinary boundaries. "The educational system has great potential for bringing about lasting cultural change" and it is important for "post-secondary institutions to incorporate accessibility into professional and technical courses of study - such as architecture, marketing, urban planning, communications, information technology, engineering, health care and education" [16]. READi is an example of accessibility training program, which has demonstrated success in its first year with indicators of achieving "thick" authentic learning. While READi targets graduate students, many of the elements can be adapted to serve the larger undergraduate engineering student population. The experience from the first year of the READi training program emphasizes the value of interdisciplinarity, the importance of engaging in real-world accessibility problems, and the need to work with people with disabilities, who provide expertise and lived-experiences.

\section{Acknowledgements}

The authors would like to acknowledge the funding support provided by NSERC CREATE READi.

\section{References}

[1] Statistics Canada, A demographic, employment and income profile of Canadians with disabilities aged 15 years and over, 2017, Cat. No. 89-654-X2018002, November 2018.

[2] UN General Assembly, Convention on the Rights of Persons with Disabilities: resolution / adopted by the General Assembly, 24 January 2007, A/RES/61/106.

[3] United Nations - Disability, Department of Economic and Social Affairs, \#Envision2030: 17 goals to transform the world for persons with disabilities. Available

at https://www.un.org/development/desa/disabilities/envi sion2030.html. Last accessed 2019-02-22

[4] Accessibility for Ontarians With Disabilities Act, 2005, SO 2005. Available at https://www.ontario.ca/laws/statute/05a11. Last accessed 2019-01-02.

[5] The Accessibility for Manitobans Act, 2015. Available at http://accessibilitymb.ca/. Last accessed 2019-04-18.

[6] Nova Scotia Accessibility Act, 2017. Available at https://nslegislature.ca/sites/default/files/legc/statutes/ accessibility.pdf. Last accessed 2019-04-18.
[7] BILL C-81 An Act to ensure a barrier-free Canada. Available at http://www.parl.ca/DocumentViewer/en/42-1/bill/C81/third-reading. Last accessed 2019-01-02.

[8] Statistics Canada, The Canadian Population in 2011: Age and Sex, Cat. No. 98-311-X2011001, May 2012.

[9] Cynthia Putnam, Maria Dahman, Emma Rose, Jinghui Cheng, and Glenn Bradford, "Best Practices for Teaching Accessibility in University Classrooms: Cultivating Awareness, Understanding, and Appreciation for Diverse Users", ACM Transactions on Accessible Computing, Vol. 8, No. 4, Article 13, 2016.

[10] Kristen Shinohara, Saba Kawas, Andrew J. Ko, and Richard E. Ladner, "Who Teaches Accessibility? A Survey of U.S. Computing Faculty", in Proceedings of the 49th ACM Technical Symposium on Computer Science Education, pp. 197-202, Baltimore MD, USA, 2018.

[11] Legislative Workgroup on Accessibility Concepts in Computer Science, Information Systems and Information Technology Programs in Higher Education, Maryland Department of Disabilities, Final Report of the Study on Accessibility Concepts in Computer Science, Information Systems and Information Technology Programs in Higher Education, August 8, 2017.

[12] Paul Ryan Bohman. Teaching Accessibility and Design-For-All in the Information and Communication Technology Curriculum: Three Case Studies of Universities in the United States, England, and Austria. Ph.D. dissertation. Utah State University, Logan, UT, 2012.

[13] M. Ahmadi, A.D.C. Chan, C. Davies, L. Frankel, A. Girouard, T.C. Graham, Y. Labiche, E. Lemaire, J. Stewart, C. Trudel, "Research and Education in Accessibility, Design, and Innovation: Integrating Post-Secondary Training in Accessibility", Canadian Engineering Education Conference, Vancouver BC, Canada, 2018.

[14] David Williamson Shaffer and Mitchel Resnick, "'Thick' authenticity: New media and authentic learning", J. Interact. Learn. Res. 10, 2 (1999), 195215.

[15] The Disability Foundation, Strategic Plan 2017-2022, Dec 1, 2017. Available at http://www.disabilityfoundation.org/SSDF_Strategic Plan-2017-2022 v32.pdf. Last accessed 2019-05-04.

[16] David C. Onley, Listening to Ontarians with Disabilities: Report of the third review of the Accessibility for Ontarians with Disabilities Act (2005), January 2019. 